\title{
Evaluation of the 'maximum price paid' as an index of motivational strength for farmed silver foxes (Vulpes vulpes)
}

\author{
Anne Lene Hovland ${ }^{\mathrm{a}, *}$, Georgia Mason ${ }^{\mathrm{b}}$, Knut Egil Bøe ${ }^{\mathrm{a}}$, \\ Geir Steinheim $^{\mathrm{a}}$, Morten Bakken ${ }^{\mathrm{a}}$ \\ ${ }^{a}$ Norwegian University of Life Sciences, Department of Animal and Aquacultural Sciences, \\ P.O. Box 5003, N-1432 Ås, Norway \\ ${ }^{\mathrm{b}}$ Department of Animal \& Poultry Science, University of Guelph, Ont., Canada N1G 2W1
}

Accepted 10 November 2005

Available online 27 December 2005

\begin{abstract}
To measure farmed foxes' motivations for full, naturalistic social contact, we constructed an apparatus where they could perform an operant to access stimuli, but then leave freely and thence determine their own bout lengths. Motivational measures based on demand curves can be invalid in such set-ups, and we therefore sought to validate the measure 'maximum price paid'. This was achieved by measuring six silver fox males' maximum operant responding for access or proximity to three resources differing in biological significance: food, vixens in oestrus and males. We predicted that if valid, maximum price paid would be highest for food and vixens. Maximum price were $970 \pm 399$ (S.E.) for food, $677 \pm 173$ (S.E.) for vixens and $389 \pm 101$ (S.E.) for other males $(P<0.05)$. In contrast, our complementary measures of motivation - price elasticity, expenditure and consumer surplus - did not differentiate between the resources, and ranked them in different orders (albeit not significantly). This was because the foxes rescheduled their behaviour with increasing costs, decreasing bout number while increasing bout length, to different extents with the three resources. Additional findings showed that all subjects 'overpaid', performing the operant response more than was required. This increased as the costs increased, perhaps due to increasing 'time outs' on the time-restricted schedule (DRH) as the task got harder. However, the overpayment was also highest when males were the resource, suggesting that operant responding was slowest and least
\end{abstract}

\footnotetext{
* Corresponding author. Tel.: +47 957632 96; fax: +47 64965101.

E-mail address: anlhovla@online.no (A.L. Hovland).
} 
efficient when working for less-valued resources. The resources present also affected how the foxes used the rest of the apparatus and influenced their behaviour; subjects staying more in the operant compartment when the resource was social (especially a female), but retreating to a distant compartment when it was food. While proximity to oestrous vixens elicited higher levels of tail wagging and only low levels of pacing, indicating a positive motivation, proximity to males elicited relatively high levels of pacing plus agonistic gaping, suggesting that the motives for seeking contact with males related to aggression. Thus, although our operant set-up reveals a drive to approach other males, the possible aggressive motives suggest that this sort of social contact would not necessarily improve their welfare in a traditional housing system. Overall, these results help improve the design and interpretation of preference tests, and confirm maximum price paid as a useful motivational measure for farmed foxes.

(C) 2005 Elsevier B.V. All rights reserved.

Keywords: Motivation; Maximum price; Operant methods; Social contact; Behaviour; Fox

\section{Introduction}

The motivation of an animal is defined as the urge to perform a given behavioural action (e.g. modified from Hurnik et al., 1995). Measuring motivational strength has become a widespread tool in animal welfare research (e.g. Fraser and Matthews, 1997), since it quantifies the extent to which animals prefer, or wish to avoid, specific stimuli or resources. For example, Cooper and Appleby (1996) evaluated the need for nest boxes in laying hens by investigating their motivation to squeeze through narrow gaps to reach the boxes. Estimating motivational strength is generally achieved via operant set-ups requiring performance of a learned task to access a resource (e.g. Hansen et al., 2002). Typically, these costs are experimentally altered, and the intensity of responding in relation to these altered costs is then used to derive various indices of motivational strength.

However, the design of these operant set-ups, and the validity of the various resultant motivational indices is a subject of discussion (Rachlin et al., 1976; Lea, 1978; Dawkins, 1983; Mason et al., 1998 and replies; Kirkden et al., 2003; Cooper, 2004). One issue concerns the type of access subjects are allowed once they have worked for a reward. Each time the animal pays a cost, it may gain a fixed portion of reward, the size of which is predetermined by the experimenter (e.g. a set time period to interact with the resource). This arrangement has the advantage of a strict covariance between price and resource consumption, e.g. the only way the animal can gain two units of reward is by paying the cost twice. This is important for the validity of some measures of motivation (Mason et al., 1998; Matthews, 1998; see below). However, this set-up's disadvantage is that subjects cannot control their own bout lengths, which may devalue some resources (Sherwin and Nicol, 1995, 1996; Mason et al., 1998). For example, setting a fixed bout length for social contact may alter its functional consequences and thence its value, with too short a time allowed per bout potentially interrupting ongoing behaviour and thence making it less rewarding (Mason et al., 1998; see also Jensen et al., 2004a,b on lying in cattle). On the other hand, setting the bout length too long prevent the subject from terminating the interaction when it wishes (e.g. retreating from aggression). For behavioural opportunities like lying or social contact, a possible solution to this problem is therefore to allow animals 
to work for bouts of access that they can terminate or prolong at will (cf., e.g. Mason et al., 2001). However, the disadvantage of this type of set-up is that cost paid and amount of resource consumed now do not necessarily co-vary because at high cost levels, animals tend to reduce their visits while prolong visit duration (Cooper and Mason, 2000), resulting in a shift in true unit price over the demand curve (e.g. Hansen et al., 2002).

Further issues concern the best motivational measure, in terms of validity (e.g. Kirkden et al., 2003) and suitability for addressing different types of welfare questions (e.g. Warburton and Mason, 2003). The measure most frequently used is 'price elasticity of demand' (e.g. Dawkins, 1983; Matthews and Ladewig, 1994; Jensen et al., 2004a), derived by plotting the consumption of the test resource against its costs (a 'demand curve', e.g. Varian, 1999) and calculating the rate of decline in consumption per unit increase in cost (e.g. Lea, 1978). This measure has intuitive appeal, but has several disadvantages. For example, it requires a set-up in which the cost paid and the amount of resource gained covary in a linear way, and thus for the 'portion size' to be determined by the experimenter (see above). More importantly, although this measure is taken from human economics, it is not actually the measure economists use to quantify resource value (because subject to confounds; see, e.g. Ng, 1990; Kirkden et al., 2003; Warburton and Mason, 2003). Instead, human economists use 'consumer surplus', the first of alternative motivational indices we discuss below.

Katz and Rosen (1998) define the consumer surplus as the difference between the amount of money a consumer is willing to pay and what she/he actually has to pay (Katz and Rosen, 1998). When asking the welfare question 'How much would the consumer benefit by getting an unlimited quantity of $\mathrm{X}$ for free?' the consumer surplus is thus the whole area under the demand curve between zero cost and the maximum the subject will pay (see Kirkden et al., 2003 for further discussion). The consumer surplus can also be used to compare the value of the first and subsequent units of one resource with the first and subsequent units of other resources (Kirkden et al., 2003). For clarity, the consumer surplus of the first visit to (or unit of) a resource is equal to the maximum price paid. Each visit has its own reservation price, which can be estimated from the inverse demand curve (for details, see Kirkden et al., 2003, pp. 161-162). This measure has the key advantage of economic validity, but again requires a set-up where the cost paid and the amount of resource gained must co-vary. A third possible derivative of the demand curve is the total expenditure; defined as the total amount of money (or another currency) a consumer spends on a given commodity (Katz and Rosen, 1998). Human economists do not use expenditure as a measure of resource value, but to analyse consumption patterns (e.g. Narayana and Vani, 2000). For animal subjects, total expenditure per unit time (expenditure rate) may be viewed as the 'total work output' an animal will expend to reap the benefits of a certain consumption rate, and some applied ethologists have therefore used it as a supplementary measure of motivation (see Mason et al., 2001; Warburton and Mason, 2003).

Our last measure does not rely on constructing demand curves. This is the maximum price paid: the highest price a subject is willing to pay for resource-access. This has previously been used as a motivational indicator in operant studies of farm animals (Bruce et al., 2003; Mason et al., 2001; Cooper and Mason, 2001; Warburton and Mason, 2003; Bokkers et al., 2004), and in human economics is termed the subjects' 'reservation price' for the first unit of a good, and is the highest price a person will accept and still purchase the 
good (Varian, 1999). The maximum price approach avoids the problems associated with the finding of suitable measures of resource consumption (time spent or visit number) from which elasticity coefficients may be derived (Cooper and Mason, 2001; but see Matthews, 1998). Thus, when assessing the value of non-divisible resources like social contact, where we wish reward size to be under the subject's control, the maximum price may therefore be the most appropriate measure because it avoids assumptions about unit price in demand curves (e.g. Mason et al., 1998).

Our aim here was therefore to evaluate the maximum price paid as a motivational index for farmed foxes. We wanted an index that could validly be used in set-ups where farmed foxes (Vulpes vulpes) control their own bout lengths when working for various types of social companion, since our ultimate aim was to investigate in detail their motivation for full physical contact with other foxes in an applied setting (Hovland et al., 2005). However, we wanted to validate this measure beforehand because preliminary tests showed that the maximum price paid tended to increase with ascending trial number, resulting in an ambiguous rank order for the test resources (Hovland et al., 2005). Also, the maximum price had received some past criticisms (Matthews, 1998), thus pinpointing the need for an evaluation prior to using it as an index of motivation in foxes.

If maximum price paid is indeed a valid measure of foxes' motivation, we would expect it to be highest for a physiologically essential resource, such as food or water-the most fundamental reinforcers that can be applied in operant experiments (Lea, 1978; Dawkins, 1983; Bokkers et al., 2004). Another biologically important resource is sexual partners (for review of their use in operant experiments, see Pfaus et al., 2001). In the seasonal breeding $V$. vulpes the opportunity to mate is restricted to a couple of months in spring (Osadchuk, 1999), and furthermore, individual females are receptive for just two to three days (Farstad, 1998). This makes seeking and monitoring females a highly adaptive response for males, and so during the breeding season the sexual motivation of males should therefore be high-perhaps so high that the prospect of mating equals or overshadows the value of food. Finally, as a low value comparator resource, other males were chosen. In general, free-living groups of $V$. vulpes consist of a dominant male with one to several vixens (Macdonald, 1979; Von Schantz, 1981) and occasionally subdominant males (Harris and Smith, 1987). However, in urban areas, groups may consist of up to 10 individuals where the alpha males share their territory with several other subdominant, adult males (Baker et al., 2004). Encounters between unfamiliar male territory holders are often aggressive, especially during the mating season (White and Harris, 1994). Consequently, the motivation of adult males to contact other unfamiliar males at this time should be low based on motives of a positive social background. Thus, if maximum price is a valid measure of motivation, it should be lowest for access to other males. However, if other adult males are regarded as potential competitors, the motivational strength to make contact may never the less be present if based on a drive to investigate, and possibly fend off, the unfamiliar male. The motives for social contact should therefore be emphasised (see below).

Our experiment had two additional, subsidiary aims. The first was to examine how bout length varied with access cost. As mentioned above, when a bout is made costly the number of bouts typically declines but the length of each typically increases (e.g. reviewed by Mason et al., 1998), resulting in a shift in true unit price such that measures derived from its 
demand curve are unlikely to be valid. However, this rescheduling occurs to different extents with different types of resources (Cooper and Mason, 2000), and in some set-ups this issue has proved not to be a major confound (e.g. Mason et al., 2001). Second, we wished to make behavioural observations to evaluate the motives of social contact. This is important for assessing the potential welfare consequences of full contact between animals.

\section{Materials and methods}

\subsection{Experimental subjects, feeding and housing}

Six two-year-old silver fox males of a domesticated line (Trut, 1999) were chosen as operant test animals. The domesticated foxes were chosen because they were more easily trained compared to foxes from the standard commercial line. Six two-year-old silver fox vixens and six silver fox males (aged two to four years), all from a standard commercial line, acted as stimulus foxes. During the experiment water was replenished three times a day whereas food was given once a day. Test foxes had access to food and water only in the operant cage (except when food was the resource), to ensure that they always returned to the operant cage and thus re-paid access costs for renewed resource contact. All foxes had access to a chewing stick throughout the experiment. Between experiments the foxes were individually housed in standard wire mesh cages measuring $61 \mathrm{~cm} \times 86 \mathrm{~cm} \times 132 \mathrm{~cm}$ situated in a standard fox house outside the test arena, with access to food and water, a wooden nest box and a chewing stick.

\subsection{Apparatus}

Our research group developed an apparatus (Hovland et al., 2005) based on some basic principles for valid generation of data in operant set-ups (for review, see Mason et al., 1998; Cooper, 2004). The device was a closed economy consisting of four cage units made of standard, plastic covered wire mesh (see Fig. 1). The central operant cage, which was the starting point of the test fox, attached to a resource cage and a control cage, each of which joined in turn to a potential stimulus fox cage. During this study all cages were used except the stimulus fox cage adjacent to the control cage (to the right in Fig. 1). In the operant cage two operanda were located on opposite walls. The stimulus fox cage to the left (in Fig. 1), adjacent to the resource cage, was the home cage of the stimulus fox. Feeding trays, drinking cups, mesh resting platforms and gnawing sticks were therefore mounted here, as well as in the test subject's operant cage. The resource under test was thus either food placed inside the resource cage, or a vixen or another male caged individually in the stimulus fox cage. When food was the resource, the stimulus fox cage was empty. The test animal thus had access to the resource cage and the control cage, but could not physically access the stimulus fox. Increasing costs were to be imposed for access to the resource cage, but the control cage maintained with almost free access (FR1). This was to control for the effect of the extra space provided in the resource cage, and thus to ensure that the motivation to access the resource cage was attributed to the presence of the resource and not the cage itself. 


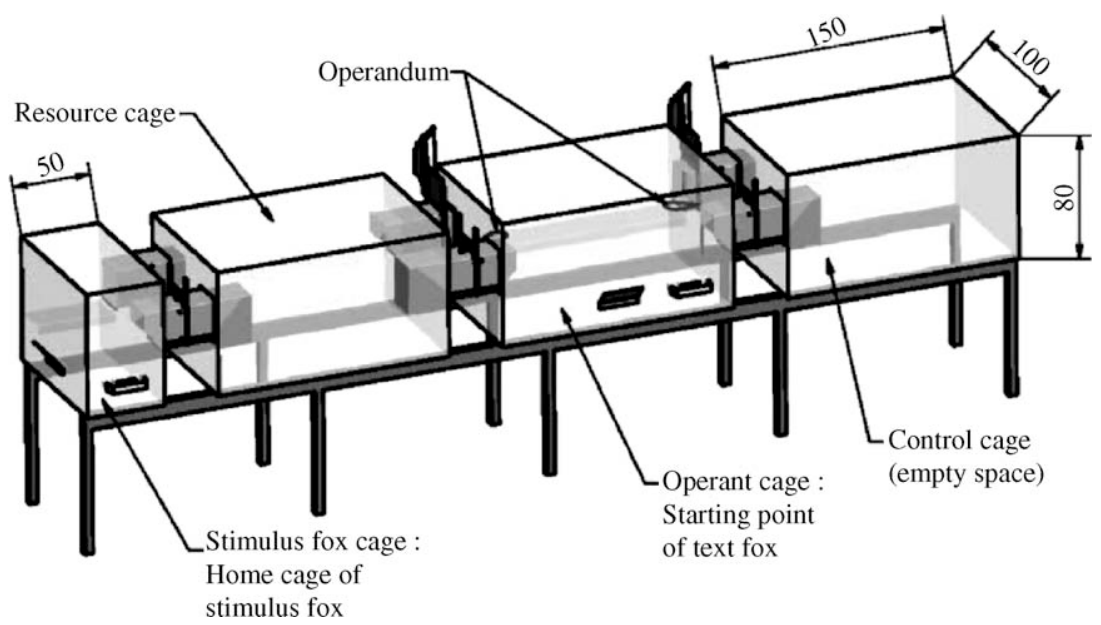

Fig. 1. The operant apparatus for foxes. Cage measurements are given in centimeter.

Two aluminium one-way gates, one for entrance and one for exit connected each pair of cage units. All gates were equipped with a micro-switch for exact logging of time data. The test foxes were provided with a collar for opening of the exit gates. All collars were equipped with a transmitter in a PVC cover measuring $50 \mathrm{~mm} \times 30 \mathrm{~mm} \times 57 \mathrm{~mm}$. Collars were made of $3 \mathrm{~mm}$ polyethylene material and the total weight was $120 \mathrm{~g}$. A rubber-coated metal chain $(42 \mathrm{~cm})$ shaped as a loop was chosen as the operandum. This was constructed to vary the strength of a validated pull, but was set to a fixed $0.5 \mathrm{~kg}$ force during the experiment. To register the number of completed pulls, a micro-switch was mounted on the operandum, in turn connected to a computer (LabView, National Instruments). To allow the fox entrance into the resource (or control) cage the computer counted the required number of pulls and signalled to the gate controller mounted on top of the gate to open the door to the resource (or control) cage.

Each apparatus was mounted on stilts $1 \mathrm{~m}$ above ground level and a total of six parallel units of the apparatus were used. All were placed $2 \mathrm{~m}$ apart in parallel rows inside an uninsulated fox shed. The experimental animals thus could see and hear each other during the experiments, and were therefore not in a completely closed economy with respect to social contact. However, since our ultimate aim was to use the apparatus to measure farmed foxes' motivation for full physical contact with other foxes around them, i.e. in a farm-like setting, these conditions had the most external validity and paralleled the test conditions planned for future experiments.

\subsection{Training of the subjects}

The experimental subjects had already been used in an operant experiment (Hovland et al., 2005), prior to which they had been trained. During the first training period the operant response was shaped in the home cage, using a rubber tube similar to the one covering the operandum and titbits as a reward. The foxes were then put in the apparatus for three weeks to learn how to enter the one-way gates, being trained (by shaping) to pass 
through them. During this training period access was limited to the gates connected to the stimulus fox cage. For the next three weeks, foxes were put in the operant cage with access to the resource cage for further conditioning of the pulling response. During this conditioning, the response schedule (DRH level, see details Section 2.4) was gradually increased from 1 to 32 pulls. Thus for the current experiment, all the test foxes were well trained and well experienced, with stable digging responses to the operanda and no fear of the doors nor of sounds made by the functioning apparatus.

\subsection{Altering costs of access}

The reinforcement schedule used was 'differential reinforcement of high rates' (DRH; Chance, 1999) whereby a certain number of pulls must occur within a fixed amount of time. A punishing effect can thus arise if responding is too slow or the subject deliver pulls at random, because when the timer zeros out, the subject has to start all over again to complete the schedule. By using the DRH schedule, one therefore ensures that the animal keeps on working at a constant rate, and it may generate extremely high rates of responding (Chance, 1999). Based on preliminary tests, a schedule allowing 4 s per pull was chosen, exemplified by a demand of 512 pulls within ca. $32 \mathrm{~min}$.

Prior to the start of trials, the foxes were put on a fixed ratio (FR) 1 schedule for a habituation period of 24-36 h. Subsequently, each cost was imposed for $24 \mathrm{~h}$, and increased until each fox stopped visiting the resource. Then, the response schedule was set to FR1 until all of the remaining subjects had completed the trial. Based on preliminary tests (Hovland et al., 2005) showing significant differences in individual pulling performance, two parallel (but different) schedules for increasing the costs were used. In the 'low schedule', costs were raised relatively gradually (FR: 1-8-16-32-64-96 $\cdots+32$ until maximum price), compared to the 'high schedule' (FR: 1-16-64-128-224$320 \cdots+96$ until maximum price). Two foxes were put on the 'low schedule' and the other four, on the 'high schedule'. This procedure was chosen to avoid a possible artefactual loss of motivation due to too heavy cost intervals in the low pulling 'low schedule' individuals, while also ensuring that the high pulling individuals would reach maximum price within a reasonable time period (four weeks). Note that these different schedules were not confounds as each fox was used as its own control.

\subsection{Experimental trials}

The first trial, measuring motivation to seek oestrous vixens, was carried out from February 22 to March 12, 2004, including two habituation days at the start and two days at the end. All stimulus vixens were in pre-oestrus at the start of the trial. Due to variation in oestrus development and the risk that some vixens would not come into full oestrus, the vixens were rotated on a daily basis to standardise the treatment between subjects. Consequently, each morning at approximately 08:30 h each test male received a different vixen as the stimulus fox. The heat status was recorded every second day during the experiment. Two of the vixens showed top heat on the 9th and 11th experimental day and the rest were in top heat on the 14th experimental day. The second trial measuring motivation to seek males was conducted between March 23 and April 4, 2004. The 
stimulus males were again rotated on a daily basis, parallel to the procedure used during the first trial. All stimulus males were breeders, and four had mated vixens prior to the experiment. The subjects were not allowed full physical contact with stimulus foxes for two reasons. For vixens, we wanted to measure the motivation to seek vixens in heat and not the motivation for the opportunity to mate, which would have required a completely different set-up; while for males, full physical contact was avoided because of potential damaging consequences of aggression. Finally, testing the foxes' motivation for food was completed between April 27 and May 22, 2004. The food used was a standard wet paste for fur animals (Pelsdyrfor Hamar BA). Based on preliminary tests, a ration of approximately 250-300 g was offered once a day, fulfilling approximately $90-100 \%$ of daily maintenance need. This procedure was chosen to avoid food leftovers, and also to ensure that the foxes stayed hungry and motivated to feed. The food was put in a metal dog bowl (diameter $24 \mathrm{~cm}$ ) tethered to the wire mesh floor in the middle of the resource cage. Any food leftovers were removed prior to the daily refill of fresh food. Note that the order of resource presentation was not randomised due to the limited period of heat in foxes, and because the fluctuation in male testosterone during the reproductive season could have caused a change in motivation for contacting males. The Norwegian Animal Research Authority approved the experiments.

\subsection{Data collected}

\subsubsection{Measures of motivation and duration of visits}

The number of visits made to each resource when it was almost free was recorded at FR1 at the start ('baseline visit rate, start') of each experiment and the second day after the maximum price was paid ('baseline visit rate, end'). The number of visits made was also calculated for each cost. To investigate how access cost and bout number affected bout length, time data for entry and exit to the resource cage were recorded for each test fox, so that the total and mean duration of visits could be calculated. As described above, in addition to the resource cage, the test fox had almost free access (FR1) to an empty cage (the control cage) during all experimental trials. The number of visits to and time spent (total and mean time per cost level) to this cage were also calculated to investigate whether the test subjects altered the use of the control cage when access to the resource became costly.

All calculated measures of motivation involved using the cost paid by the animal. However, the price that the test foxes paid in practice was typically higher than the cost level set by the observer: the foxes often pulled the operandum more than was required, 'over-paying' to access the resource cage. All motivational indices were therefore calculated using both: (a) the 'set cost', i.e. the FR set by the experimenter and (b) the 'actual cost', i.e. the cost paid in practice by the subject. The 'actual cost' was estimated for each cost level as the total number of pulls divided by the number of visits made to the resource cage at that cost level. The effect of 'over-payment' was also investigated to see whether the subjects tended to over-pay more for some of the resources under test.

For each fox and resource, the maximum price paid was recorded as the price paid the day before the fox stopped visiting the resource cage; the expenditure rate was calculated 
as the number of visits, multiplied by the cost of access, divided by the number of days in the trial; the price elasticity of demand was calculated based on number of visits to the resource cage plotted against price per visit on a log-log plot, the slope of which was ascertained by linear regression; the consumer surplus was estimated for by multiplying the increase in price times number of visits at that price for each price level to give the area under each demand histogram (estimating the area under the curve). To illustrate how the consumer surplus of successive visits declined, the following procedure was used to fit monotonic inverse demand curves to the experimental data. For each resource, price was plotted against demand averaged across the six subjects. A number of functional forms were fitted and the form with the best fit was selected. In all cases, the best fitting form was a cubic function of the log of price against the log of mean demand (vixens: $r^{2}=0.991$; males: $r^{2}=0.994$; food: $r^{2}=0.984$ ). These curves are intended only to demonstrate a general decline in the value of successive visits, not to accurately quantify the maximum price paid or consumer surplus for each visit. A plot of price against mean demand treats one subject with a demand of 2 as equivalent to two subjects with a demand of 1 , which results in an overestimate of the number of subjects that will pay a particular price for the first visit compared with a measure of the average maximum price paid or consumer surplus obtained from individual demand curves.

\subsubsection{Behaviour with the social resources}

Subjects were videotaped continuously ( $24 \mathrm{~h}$ time-lapse) during the experiment using three video cameras connected to a multiplexer and video recorder. Behaviour was recorded during the five first minutes after entry to the resource cage using instantaneous sampling with 6 s sample intervals. The recordings were completed at four separate cost levels (FR1-DRH16-medium DRH-high DRH), which gave a total of 20 min observation time for each subject and resource. All behaviour recordings were made by the same assistant, blind to the hypotheses under test.

Postural behaviours (lie, sit, stand, walk and run) were recorded in order to investigate whether increasing access costs affected the subject's tendency to rest during resource interaction. Behaviours potentially related to motivational states were also recorded, as follows:

1. Pacing: Stereotyped, short-distance walking from side to side (e.g. Hurnik et al., 1995) in front of the stimulus fox's cage wall; often an intention movement of escape or frustrated access (e.g. seen in female mink shut out from their young; Mason, 1993).

2. Gate digging: Lying, sitting or standing in front of the stimulus fox's cage and digging with one or both front paws inside or on both gates leading to this cage (e.g. Hansen and Jeppesen, 2000 recording minks scratching on blocked tunnels leading to food).

3. Tail wagging: Rapid swinging of the tail from side to side (Hurnik et al., 1995). A low positioned, rapid swinging of the tail is an aggression-suppressing signal elicited in canids during submission (greeting) (Fox, 1971).

4. Gaping: Open mouth signal observed in relation to submission, defensive or offensive aggression (Fox, 1975, p. 437). This signal is distinct from the open mouth 'play face' which was not observed during the study. The total number of gapes during the $4 \times 5$ min observation period was recorded. 


\subsection{Statistical analyses}

The motivational indices were calculated for each individual and treatment. Treatment effects were assessed using SAS Software's mixed procedure (Littell et al., 1996) applying the model: Value $=$ Resource $_{1-3}+$ Fox $_{1-6}$, defining Fox as a random effect. No interaction effects were tested due to the limited denominator degrees of freedom. A Satterthwait approximation was used for calculation of the denominator degrees of freedom (Littell et al., 1996). For pre-planned comparisons of least square means (Proc Mixed-default option) we used one-sided $P$-values where the direction of the difference was predicted beforehand (food versus males and vixens versus males). All motivational indices were log-transformed for statistical tests due to non-normality of residuals. For elasticity, baseline visit rate was added as a covariate to control for the effect of high visit rates at FR1. However, in all figures, means and standard errors are presented as original values. Due to the maximum price paid approach, some of the higher cost levels included data from only one individual. In the figures, mean values for visit duration and visit number per cost level are therefore represented based on a minimum of two individuals, leaving out values of single individuals. However, for the statistics all data were included.

The time data were analysed using the basic model Time $=$ Resource $_{1-3}+$ Fox $_{1-6}+$ Cost $_{1-\text { max }}$, with Fox as a random effect. Interaction effects were tested for when appropriate. The behaviour data were examined in a mixed model where Behaviour $=$ Resource $_{1-3}+$ Fox $_{1-6}+$ Cost $_{1-4}+$ Resource $_{1-3} \times$ Cost $_{1-4}$, again using Fox as a random effect.

Correlations between the various operant motivational indices and between the operant indices and behaviour were examined using the Pearson correlation coefficient $(r)$. Prior to each correlation, the motivational indices were transformed for each subject and resource by the formula 'motivational index'/'maximum index value', giving the highest value a score of 1 and the other two values a score between 0.10 and 0.99 . This was done to control for the effect of individual pulling performance. SAS ${ }^{\circledR}$ Enterprise GuideV2 was used for the statistical analyses.

\section{Results}

\subsection{The motivational indices for the different resources}

\subsubsection{Maximum price paid}

There was a significant effect of resource on 'set' maximum price paid $\left(F_{2,12}=4.25\right.$, $P=0.040)$. Pair wise comparisons showed differences in the predicted direction between the maximum price paid for males and food (one-sided $t_{12}=-2.85, P=0.007$ ) and males and vixens (one-sided $t_{12}=1.97, P=0.036$ ), but no significant difference between food and vixens $\left(t_{12}=-0.88, P=0.395\right.$; Fig. $\left.2 \mathrm{a}\right)$. In contrast, there was no significant effect of resource on the 'actual' maximum price paid $\left(F_{2,12}=1.96, P=0.184\right.$; Fig. 2a).

\subsubsection{Price elasticity of demand}

There was a significant effect of baseline visit rate (start) on the elasticity coefficient for food $\left(F_{1,6}=27.12, P=0.002\right)$, with higher number of visits at FR1 predicting higher 

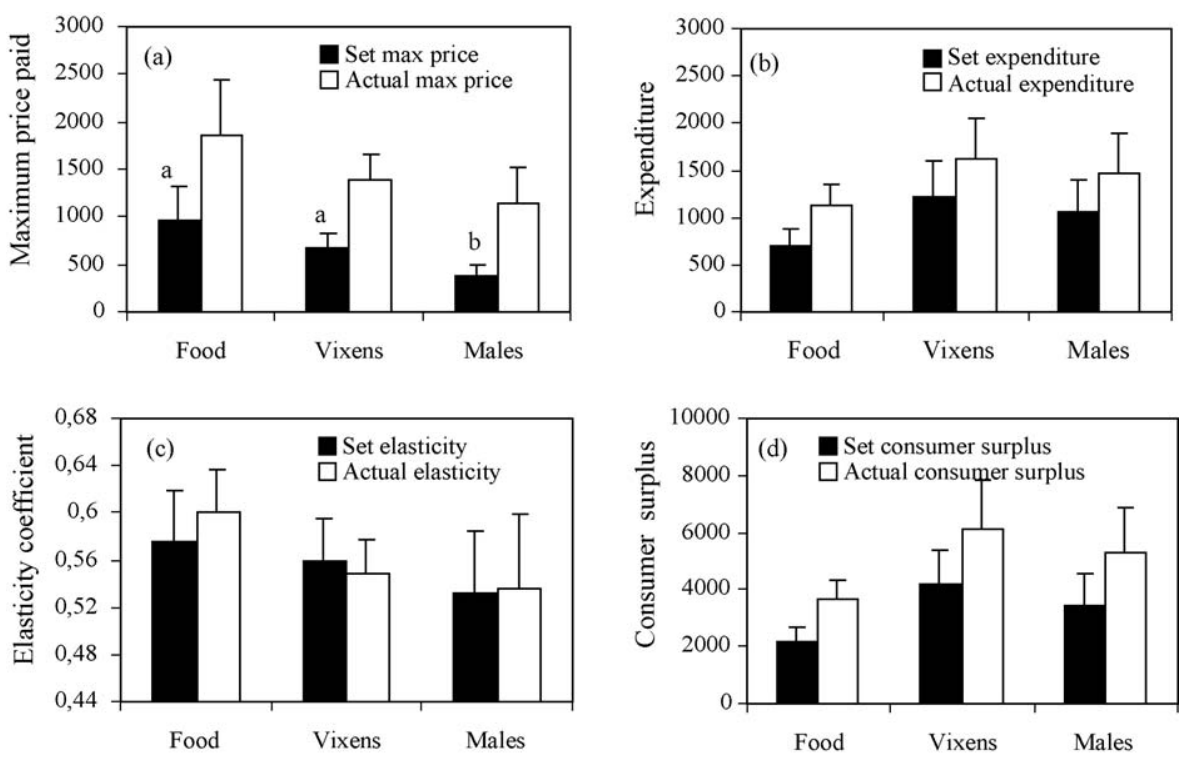

Fig. 2. (a) The 'set' and 'actual' maximum price paid, (b) the 'set' and 'actual' expenditure, (c) the 'set' and 'actual' price elasticity coefficient when controlling for baseline visit rate (lower value indicate less elasticity) and (d) the 'set' and 'actual' consumer surplus for the different resources. The vertical lines indicate the standard error of the mean. Bars with different letters ( $\mathrm{a}$ and $\mathrm{b})$ are significantly different $(P<0.05)$.

price elasticity. This effect was not significant for vixens $\left(F_{1,6}=0.18, P=0.683\right)$ or males $\left(F_{1,6}=0.01, P=0.920\right)$. There were no effects of resource on 'set' elasticity $\left(F_{2,18}=0.30, P=0.744\right)$, even when baseline visit rate was corrected for $\left(F_{2,11.4}\right.$ $=1.93, P=0.190$; Fig. 2c). For the 'actual' price elasticity there was again no significant effect of resource (e.g. controlling for baseline visit rate: $F_{2,11.2}=2.38, P=0.138$; Fig. 2c).

\subsubsection{Expenditure rate}

The 'set' and 'actual' expenditure indices were not significantly different between the three resources ('set' expenditure: $F_{2,12}=2.47, P=0.126$; 'actual' expenditure: $F_{2,12}=1.91, P=0.190$; Fig. 2b).

\subsubsection{Consumer surplus of all visits}

There was a tendency towards an effect of resource on the 'set' consumer surplus $\left(F_{2,12}=3.05, P=0.085\right)$. The consumer surplus of all visits to the resources was lower for food compared to that for vixens $\left(t_{12}=2.42, P=0.032\right.$; Fig. $\left.2 \mathrm{~d}\right)$, whereas no significant differences was found between males and food or males and vixens. For a graphic illustration of the 'set' consumer surplus of subsequent visits to the resources the inverse demand curve for the three resources is shown in Fig. 3. For the 'actual' consumer surplus there was no significant effect of resource $\left(F_{2,12}=2.12, P=0.162\right.$; Fig. 2d). 


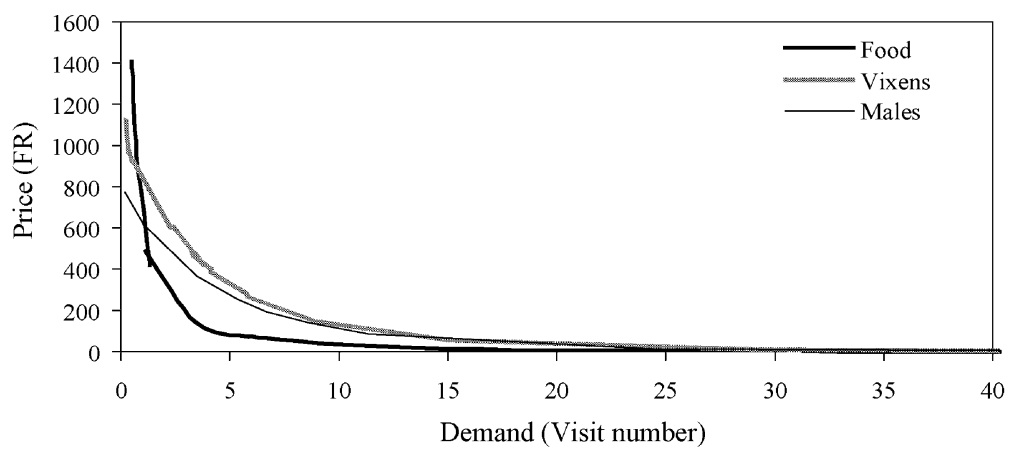

Fig. 3. The estimated inverse demand curves for the different resources (vixens: $r^{2}=0.991$; males: $r^{2}=0.994$; food: $\left.r^{2}=0.984\right)$. The figure illustrates how the consumer surplus of successive visits declined.

\subsubsection{Correlations between the various motivational indices}

Correlation analyses between the various motivational indices were run for each resource using the 'set' values (transformed values, see Section 2.7 for details), since the 'set' maximum price was the only index which differed significantly between resources. There was no general pattern of correlation between the various motivational indices, although a positive correlation between maximum price paid and the total expenditure was found for males $(r=0.94, P=0.004)$. Also, the total expenditure and the consumer surplus for all visits was significantly correlated for vixens $(r=0.99, P<0.001)$, with a tendency found for males $(r=0.76, P=0.081)$.

\subsubsection{Factors affecting over-payment for resource-access}

Overpayment could have merely been a cost-dependent effect of using the time limited FR schedules (DRH), with a high 'timed-out' (and thence failure) rate as the effort required to successfully complete the schedule is increased. Alternatively, a tendency to take long breaks (and thence be timed-out, so that pulling had to be re-started) could also reflect low motivation. To therefore test whether over-payment varied with cost or with resource, we used the mixed model 'Over-payment $=$ Resource $_{1-3}+$ Cost $_{1-\max }+$ Fox $_{1-6}+$ Resource $\times$ Cost $)+($ Resource $\times$ Cost $\times$ Fox $)$, defining Fox as a random effect. The results showed a tendency towards a resource effect $\left(F_{2,172}=2.47, P=0.088\right.$; males $=510 \pm 211$, vixens $=472 \pm 182$, food $=299 \pm 167)$, but no significant 'Resource $\times$ Cost' interaction $\left(F_{2,172}=1.07, P=0.345\right)$. Further, a significant effect of cost was found $\left(F_{2,172}=10.94\right.$, $P=0.001)$, including a significant 'Resource $\times$ Cost $\times$ Fox' interaction effect $\left(F_{15,172}=3.89, P<0.001\right)$.

\subsection{The effect of increasing costs on the foxes' use of the resource compartments}

\subsubsection{Visit rates to the resource cage}

There was no general effect of resource on the number of visits to the resources at the initial cost level FR1 $\left(F_{2,12}=0.37, P=0.697\right)$, where the mean number of visits was $54 \pm 4.5$. There was no effect of resource on baseline visit rates the second day after maximum price was reached (FR1, end: $\left.F_{2,11}=2.30, P=0.146\right)$, but the overall visit rate was 

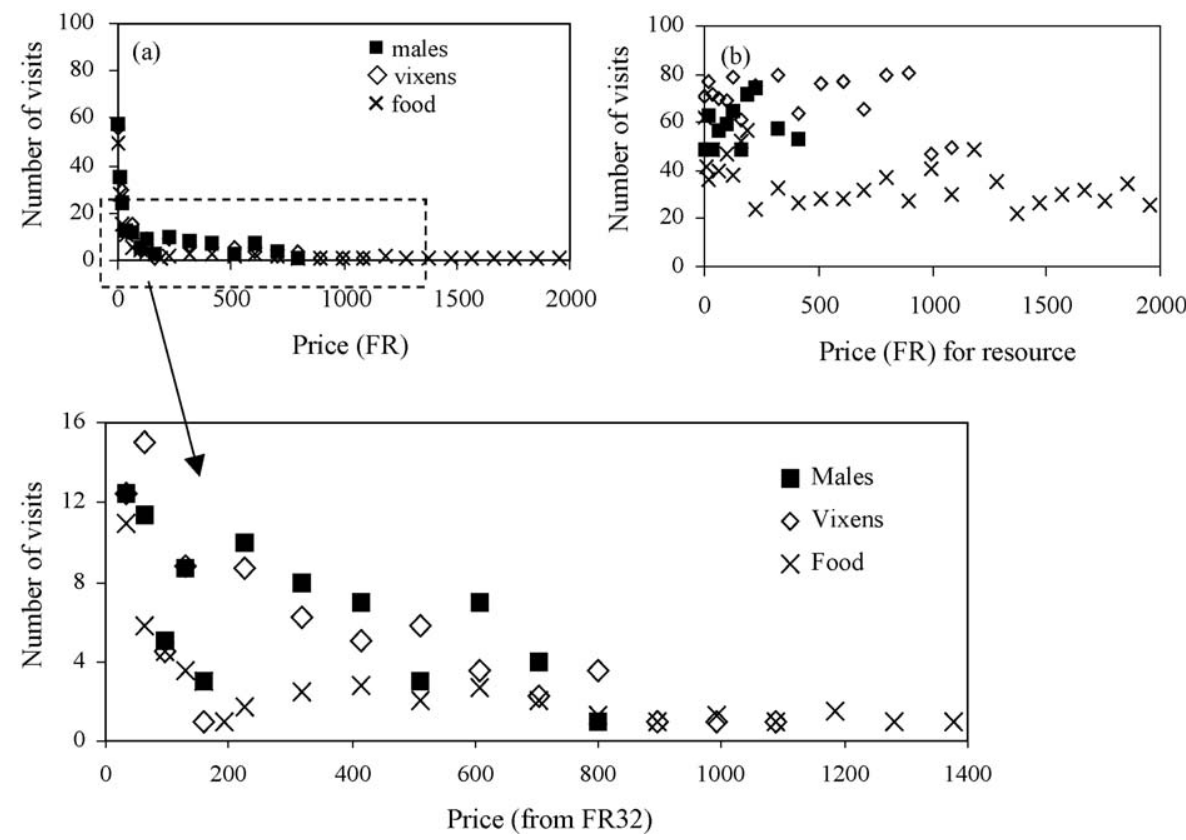

Fig. 4. (a) Mean number of visits to the different resources with increasing access costs. For clarity an enlarged section of (a) is shown below. (b) Mean number of visits to the free control cage with increasing access costs to the resource cage.

significantly lower than the baseline visit rate at the start $\left(38 \pm 3.8\right.$, paired $t$-test, $t_{16}=3.40$, $P=0.004)$. The foxes visited all three resources less frequently as the cost of visits increased $\left(F_{1,189}=40.47, P<0.001\right.$; Fig. 4a). There was a significant effect of 'Cost $\times$ Resource' on number of visits to the resources $\left(F_{2,175}=11.18, P<0.001\right.$; Fig. 4 a, enlarged section), i.e. the slope of visit number against cost varied between the three resources.

\subsubsection{Time spent with the different resources with increasing costs}

Total time spent with the resources also decreased significantly for all resources with increasing visit costs (vixens: $F_{1,61}=22.50, P<0.001$; males: $F_{1,45}=8.16, P=0.007$; food: $F_{1,81}=7.09, P=0.009$; Fig. 5a-d) and differed significantly between the resources $\left(F_{2,189}=35.33, P<0.001\right)$. However, the mean duration of visits to the resources increased significantly with increasing costs for males $\left(F_{1,45}=2.43, P=0.020\right)$ and females $\left(F_{1,56}=6.81, P=0.012\right)$ but not for food $\left(F_{1,76}=0.33, P=0.568\right.$; Table 1$)$. Note that for Fig. 5 values for total time spent inside the free control cage are also given (for details, see Section 3.3.2).

\subsection{The effect of increasing costs on the foxes' use of the control cage}

\subsubsection{Visits to the control cage with increasing costs}

There was a significant difference between resources in the number of visits made to the free control cage $\left(F_{2,186}=44.58, P<0.001\right.$; Fig. $\left.4 \mathrm{~b}\right)$. The average number of visits 


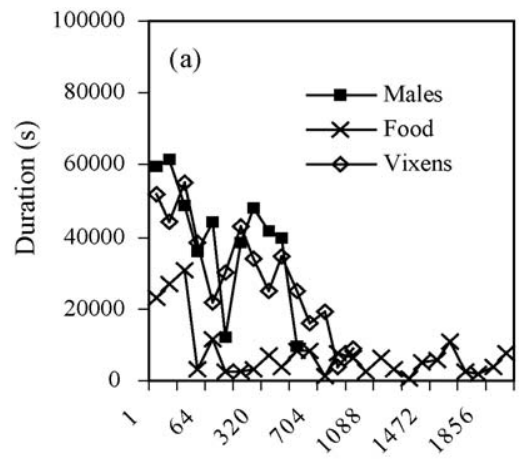

Price (FR)

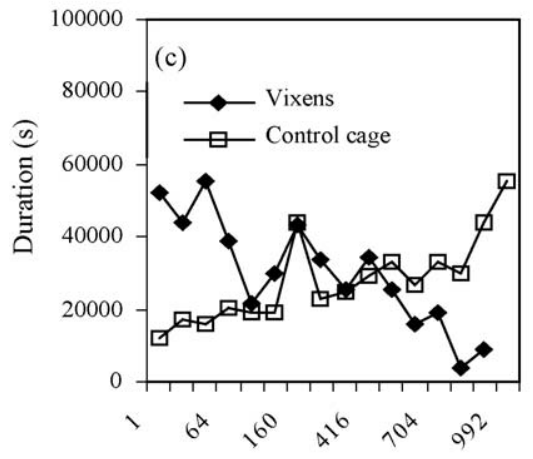

Price (FR)

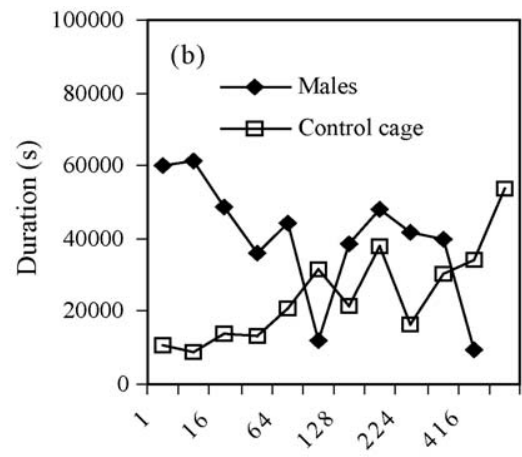

Price (FR)

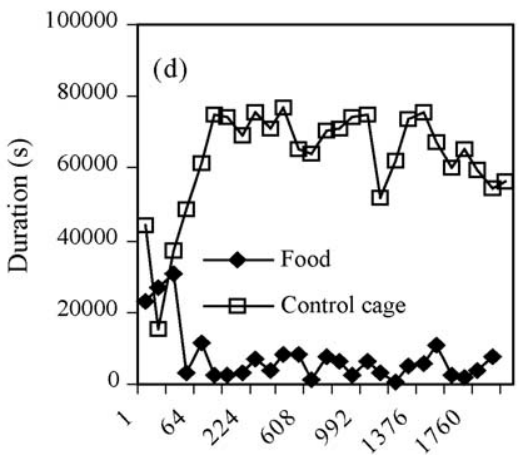

Price (FR)

Fig. 5. Total time spent close to or with (a) the different resources. For comparison the total time spent inside the resource cage is plotted against the time spent inside the free control cage and is shown for (b) males, (c) vixens and (d) food.

Table 1

The mean $( \pm$ S.E.) duration (seconds) of visits to the different resources for four cost levels

\begin{tabular}{lllrl}
\hline Cost level & \multicolumn{2}{l}{ Mean \pm S.E. } & & \\
\cline { 2 - 4 } & Vixens & Males & \multicolumn{1}{c}{ Food } \\
\hline FR1 & $1138 \pm 277$ & $1118 \pm 181$ & $500 \pm 163$ & 6 \\
FR64 & $2922 \pm 686$ & $4298 \pm 594$ & $1681 \pm 763$ & 6 \\
FR128 & $3276 \pm 503$ & $4186 \pm 1277$ & $828 \pm 161$ & 6 \\
FR224 & $5105 \pm 337$ & $4912 \pm 540$ & $1942 \pm 815$ & 4 \\
\hline
\end{tabular}

per day and cost was $71.7 \pm 3.6$ for vixens, $59.9 \pm 3.0$ for males and $36.2 \pm 1.7$ for food. There was no effect of increasing resource costs on these visits to the control cage during the food trial $\left(F_{1,79.8}=0.03, P=0.871\right)$ or the vixen trial $\left(F_{1,57.4}=1.20\right.$, $P=0.279$ ). During the male treatment, however, there was a tendency towards an increase in visits to the control cage with increasing access costs of the resource $\left(F_{1,42}=3.97\right.$, $P=0.053)$. 


\subsubsection{Time spent in the control cage and the operant cage with increasing costs}

When the resource-access costs increased, the test foxes also spent increasingly more time inside the control cage $\left(F_{1,187}=28.16, P<0.001 ;\right.$ Fig. 5$)$. Total time spent inside the control cage per day and cost differed between the resources $\left(F_{1,187}=75.45, P<0.001\right)$, and was highest for food (Fig. 5d). Total time spent inside the operant cage per day and cost also differed between the resources $\left(F_{2,189}=16.44, P<0.001\right)$, on average $29,702 \pm 2282 \mathrm{~s}$ for vixens, $21,962 \pm 2516 \mathrm{~s}$ for males and $14,862 \pm 1829 \mathrm{~s}$ for food. Also, when access cost to the resources increased the mean visit duration to the free control cage went up for vixens $\left(F_{1,56}=29.77, P<0.001\right)$ and for males $\left(F_{1,40}=21.56\right.$, $P<0.001)$ but not for food $\left(F_{1,76}=0.53, P=0.4683\right)$.

\subsection{Behaviour towards vixens and males}

There was no effect of resource on active behaviours (walk and run: $F_{1,40}=2.47$, $P=0.124$ ) or passive behaviours (stand, sit and lie down: $F_{1,40}=0.08, P=0.781$ ) performed after entering the resource cage. In general, the foxes tended to sit and lie more after paying increasing access costs, independent of resource-type $\left(F_{3,35}=2.36\right.$, $P=0.088)$. There was a significant difference between cost level FR1 $(50.9 \pm 9.5 \%)$ and the highest cost level $(71.2 \pm 4.5 \%)$ in the percentage of sitting and lying down $\left(t_{35}=-2.07, P=0.046\right)$.

The foxes spent significantly more time pacing in front of the stimulus fox's cage when males were present compared with vixens $\left(F_{1,35}=4.90, P=0.034\right.$; Fig. 6$)$. No effect of $\operatorname{cost}\left(F_{3,35}=1.08, P=0.372\right)$ or Cost $\times$ Resource interaction $\left(F_{3,35}=0.88, P=0.463\right)$ was found on the subjects' propensity to pace in front of males. In general, there was no significant effect of resource on digging on the gates $\left(F_{1,40}=1.63, P=0.209\right)$. However, the foxes dug more on the gates during low cost levels $\left(F_{3,40}=3.44, P=0.026\right)$ and this was most pronounced when vixens in heat were present (percent digging at FR1: vixens $=18.3 \pm 8.3$; males $=7.5 \pm 4.2$ ). A tendency towards more tail wagging towards vixens was found $\left(F_{1,35}=3.32, P=0.077\right)$. When males were present, four of the test foxes showed gape signals after entering the resource cage, whereas there were no records of this behaviour towards vixens in heat (Fig. 6).

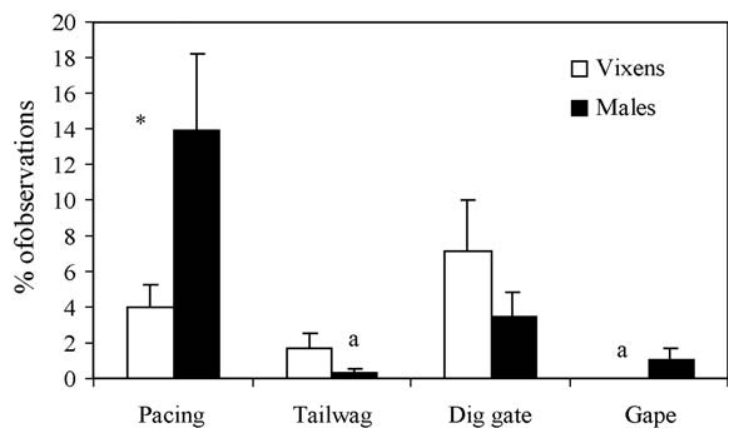

Fig. 6. Motivational behaviours of the foxes during the five first minutes after entering the resource cage near vixen in heat and males (mean \pm S.E.). For gaping, the bar signifies mean number ( \pm S.E.) of gaping signals. The asterisk denotes $P<0.05$ and the letter 'a' indicates $P<0.08$. 


\subsubsection{Correlation between motivational behaviours and 'set' maximum price paid}

We wanted to test whether motivation to access vixens or males co-varied with any of the motivational behaviours recorded on video. This was investigated for the 'set' maximum price paid since this was the only index significantly affected by resource. A general correlation analysis demonstrated a significant positive correlation between maximum price and pacing towards males $(r=0.88, P=0.022)$ and a tendency towards this towards vixens $(r=0.76, P=0.077)$. None of the other behaviours (tail wagging, gate digging or gaping) showed a significant correlation with the 'set' maximum price. However, individual differences in maximum price could have reflected pulling power and the schedule they were on, as much as individual differences in motivation. The analysis was therefore repeated using corrected values for maximum price (see Section 2.7). The resultant correlation analysis showed no significant relationship between pacing and motivation, either for males $(r=0.22, P=0.680)$ or females $(r=-0.53, P=0.282)$.

\section{Discussion}

The work reported here was aimed at refining methodology rather than reaching conclusions about farmed foxes per se; thus, some aspects of the experimental design were not optimal for the latter type of study to be maximally valid. In particular, the subjects were genetically tame, and also not completely independent, as they were all housed in the same barn and could potentially influence each other although housed separately. Also, the sample size consisting of six subjects was low. However, this was not considered a major concern in a methodological study such as this.

\subsection{The motivational indices: validity and factors affecting them}

As predicted, most experimental subjects paid the highest price to access food, reflecting the fact that food is a biological necessity. This agrees with other operant studies using food as a comparative resource (e.g. Matthews and Ladewig, 1987; Pedersen et al., 2002; Warburton and Mason, 2003). The maximum price paid for vixens was not significantly different from that paid for food, consistent with our assumption that sexual motivation should be a powerful reinforcer for silver fox males. Other studies have shown that both males and females from many species (e.g. rats, rhesus monkeys and pigeons) will work hard, by performing operant responses, to access sexually active partners (reviewed by Pfaus et al., 2001). Again as predicted, the willingness to pay for access to other males was significantly lower than for both food and vixens, reflecting a lower motivation to seek proximity to other males.

The maximum price index has received criticism for not being a suitable motivational measure. Matthews (1998), in particular, argue that its usefulness is limited, as the criterion for determining when animals cease to respond is arbitrary and because the maximum price paid varies between subjects. In the studies referred to by Matthews (1998), in which animals were tested for maximum willingness to respond on a progressive ratio response schedule for $1 / 2 \mathrm{~h}$ sessions, the experimenters used $30 \mathrm{~s}$ (Kennedy and Baldwin, 1972) and 2 min (Hutson and Mourik, 1981) as the maximum price criterion, also labelled the 
'breaking point' index (Hodos, 1961). Possibly, these time limits reflected the short test duration used $(1 / 2 \mathrm{~h})$, and did, nevertheless, produce relevant preference outcomes. In our study, where cost were increased once per $24 \mathrm{~h}$, the maximum price paid was recorded when the animal stopped visiting the resource for $24 \mathrm{~h}$, a criterion also adopted by Mason et al. (2001) and Cooper and Mason (2001). A combination of long session duration and infrequent price increases avoids the effects of short-term satiation that may occur when using the breaking-point approach. The maximum willingness to pay did however vary between our subjects, two of them pulling almost 2000 to access food whereas the maximum price paid for two of the other subjects were close to 200. This result shows that different animals perceive operant costs differently, and that subjects should function as their own control by testing their peak motivation for access to essential resources (e.g. food, water or sexual partners) in order to establish the relative strength of motivation. Also, this should be important when using the price elasticity approach because, frequently, the demand curve is calculated for only a limited range of costs (e.g. Raslear et al., 1988; Foster et al., 1997; Holm et al., 2002), a range that may be perceived differently by the experimental subjects when it comes to costliness thus resulting in individual variation in elasticity. Also, in our study, the subjects were accustomed to working on high schedules, which is important, because the intensity of operant responding on intermittent schedules may increase with subsequent trials due to the effect of training (Hovland et al., 2005) and as a general effect of intermittent reinforcement (Domjan and Burkhard, 1986). Consequently, proper training of the subjects prior to testing them for maximum operant responding is important for the maximum price to be a valid motivational index.

The other motivational indices used in this study did not distinguish between the resources. As regards the price elasticity the resulting ranking of resources was opposite to that from the maximum price paid. The expenditure rate, or the total work output for accessing the resources, paralleled the consumer surplus for all visits, however not significantly; neither of them corresponding to the maximum price paid. Looking at the patterns in the animals' behaviour helps explain these results. At low costs the visit number to all of the resources was equally high, however the increasing access costs made the subjects reschedule their behaviour by reducing the number of visits and increasing the duration of each visit, which differed between the social resources and food. When entry fee increased the visit rate to food decreased beyond that for males and vixens and stayed low throughout the study. Also, the bout length increased with increasing access costs for visits to males and vixens, but not for food. The steep decline in visit number to food resulted in a steeper slope of the demand function, resulting in a high elasticity. We attribute this effect to two main factors; different satiating effects of social resources and food, and the violation of the recommended covariance between price and consumption for computing valid demand curves. Concerning satiation (see Kirkden et al., 2003 for a complete discussion), the rewarding properties of bouts of access to unlimited amounts of food may differ fundamentally from that for social contact. When an animal consumes food it will reach satiation as a positive function of consumption, because the level of hunger declines with each subsequent mouthful due to physiological consequences. Initial bouts of social contact may, however, increase the motivation for repeated interaction due to the rewarding effect of positive or negative interaction (play: Willford et al., 1999; aggression: Fish et al., 2002). In this study, satiation for food was easily reached during the 
first few visits, confirmed by the fact that although the consumer surplus of the first visit (equal to the maximum price paid) was higher for food than for other resources, the consumer surplus of subsequent visits was lowest for food. Satiation for the social resources was probably harder to obtain, maybe due to the fact that the foxes were not allowed physical contact to accomplish their intentions. In other words, satisfactory 'consumption' of males and vixens seemed to be reached through repeated visits, confirmed by the higher consumer surplus of later visits, whereas satiation for food was likely to occur during the first visits to the food. Consequently, the higher elasticity for access to food occurred because of differing satiation rates and not because food was a low valued incentive.

\subsection{Overpayment: why did foxes pull more than they needed to?}

The 'actual' maximum price paid by the foxes during the different trials was typically higher than the price set by the experimenter: on average, the foxes paid more than twice the set price. However, in contrast to the 'set' maximum price, the 'actual' maximum price did not differ significantly between resources. Investigating the factors affecting over-payment, we found that it increased with cost, and also tended to be greatest for male access and least for food. This supports the hypothesis that over-payment resulted from using the DRH schedule, with foxes tending to 'fail' or be timed out at high costs so that they needed to restart their pulling for access-criterion to be reached. It also possibly supported our hypothesis that overpayment reflected ambivalence and low motivation, as if when working for male access, the subjects often changed their mind mid pulling session, or pulled more at random, with more pauses. Interestingly, in an operant study of laboratory mice (Mus musculus), Warburton and Nicol (1998) found that pulling efficiency (where $100 \%$ efficiency = no overpayment) was highest for food $(97.3 \%)$ and lowest for the home cage (78\%), in accordance with our findings for food. In this study, a fixed ratio schedule without time limits were used, and so here, the subjects sometimes pulled the required number but then chose not to access the resource, with this occurring least for food. In their mink work, Cooper and Mason (2000) similarly found that weighted doors (their access cost) were sometimes pushed but not entered. At very low prices, this occurred most for resources of low importance, as if animals pushed but then changed their minds. However, at high access costs, these failed attempts instead occurred most for the most preferred resources, as if here mink were trying their best to open doors but simply failing. Overpayment in operant experiments with mice is also reported by Warburton (1999) (actual cost versus schedule requirements) and Collier et al. (1990) (activity price versus resource-access price) investigating activity patterns in rats, but these authors do not discuss possible explanations for this result; and overall the reasons for this interesting phenomenon likely vary from one type of set-up to the next.

\subsection{How resource cost affected how the animals used the rest of the apparatus}

During all trials the subjects maintained a high visit rate to the free control cage, which was highest for vixens and lowest for food. However, the total time spent in the control cage 
was highest during the food trial. When vixens and males were used as the resource, the time spent inside the control cage increased with increasing costs to the resource. Such behaviour could be motivated by multiple factors. One explanation is a general avoidance of the operant cage due to its association with an operant endeavour that could result in frustration. However, this does not account for the difference between resources. A second possibility is that the foxes compensated for not being able to spend time with the resource, and therefore spent more time in the control cage when it became increasingly costly to enter the resource cage. If the subjects defined the available area as their territory, the presence of other males may have increased territorial motivation making it even more important to monitor the rest of the territory, the control cage, when it became too costly to defend the resource cage. Interestingly, the time spent inside the operant cage was highest for vixens and lowest for food, suggesting a link between the type of resource under test and the distance the subjects chose to preserve when not being able to visit the resource. During the food trial, the only thing rendering the resource cage different from the control cage was a small food bowl, an item that should not devalue use of the cage for resting or active behaviours. Nevertheless, the subjects avoided using the cage after eating, suggesting that the presence of the food redefined the cage's function. Regardless of the mechanism(s) involved, these data do reveal an unexpected link between the type of resource under test, its cost, and the distance the subjects chose to preserve when not actually visiting it. It would be interesting to see if this picture differs were the control cage placed next to the resource cage rather than distant from it.

\subsection{The animals' behaviour with the resources}

One might have expected resting to be a low priority when finally entering the resource cage after paying high costs. Cooper and Mason (2000) found that minks latency to interact with environmental resources went down with increasing access costs, reflecting a high motivation to interact with the resources. In this study latency to interact was not recorded. Nevertheless, during the five first minutes subsequent to paying high entry fees the subjects sat and lay down more inside the resource cage compared to when paying low entry fees independent of resource. This did not vary with resource, instead solely increasing with cost. Thus like our overpayment results, these could be a consequence of costly behaviour itself, reflecting a need to rest after an exhausting pulling session.

Further behavioural data from our study indicate that the motives for resource interaction varied. They appeared linked to positive emotions for vixens in heat, as inferred from a tendency towards higher levels of tail wagging, low levels of pacing, and absent gaping signals. In contrast, during visits to the males the subjects showed an elevated level of pacing in front of the stimulus fox's cage. Four of the experimental subjects also expressed gape signals, indicating aggressive interactions between test and stimulus foxes. Also, the level of tail wagging tended to be lower. Possibly, the presence of other males could have elicited sexual competition as the trial was completed at the end of the mating season, or aggression could have occurred as a result of a territorial drive to defend the resource cage. In free-living red foxes White and Harris (1994) reported that encounters between males from different family groups during the winter months was almost always aggressive. In farmed silver foxes males, gaping, spitting and attacks on the cage wall 
towards other neighbouring males is frequently observed during the breeding season (Arve Halstvedt, personal communication).

In operant studies measuring the strength of motivation the use of behavioural indicators of specific motivational states may help evaluate the validity of the operant motivation index (Zimmermann et al., 2000). Our results showed a high and significant correlation between pacing in front of the stimulus fox's cage and maximum price paid for males and a tendency for females. However, when controlling for individual variation in pulling power no significant correlation was found, confirming that pacing were not an indication of high motivation. The lower level of pacing towards vixens, which were valued more than males by a higher maximum price, shows that pacing does not necessarily reflect high motivation. Due to the possibility that motivation to access the resource cage was based on territory defence or sexual competition we speculate that frustration or arousal was a likely explanation for the high level of pacing towards other males. As subjects working for males showed stereotypies and threat-related gaping, this suggests that they were not working for the pleasure of being near them-i.e. that even though they did work for them, this would not make 'nearby males' a good environmental enrichment from a welfare point of view. On the other hand, the subjects' opportunity to work for and monitor nearby males could potentially have improved their sense of environmental controllability, which could be rewarding. The need to clarify the power structure is a natural phenomenon of social species, and is related to future fitness benefits for both contestants, provided the losers are given the chance to retreat to avoid serious injury. Because of the fitness benefits of high social status, especially for males, males should be motivated to interact aggressively with other males, and to some extent may find aggression rewarding. This is supported by the finding that male mice (M. musculus) will work for brief aggressive encounters with intruder males (Fish et al., 2002). Our findings pinpoint the need to establish the motives of social contact through behavioural observations, and not to rely on operant motivation alone when examining animals' need for contact as a possible means to improve welfare.

\subsection{Concluding remarks}

The usefulness of maximum price as a motivational index for foxes was confirmed by the biologically meaningful ranking of resources. Also, the foxes' behaviour during interaction with the social resources indicated various motives for seeking contact.

\section{Acknowledgements}

The Norwegian Research Council and the Norwegian Fur Breeders' Association funded the study. Thanks to research assistants Arve Halstvedt and Margrethe Brynem for providing excellent animal care and for monitoring the experiments. We would also like to thank research assistant Helene Kingsley Smith for valuable help in completing the behaviour recordings, and Andreas Flø and Tore Ensby for technical support. We are grateful to Richard Kirkden for discussions and valuable comments during work on the manuscript. 


\section{References}

Baker, P.J., Funk, S.M., Bruford, M.W., Harris, S., 2004. Polygynandry in a red fox population: implications for the evolution of group living in canids? Behav. Ecol. 15, 766-778.

Bokkers, E.A.M., Koene, P., Rodenburg, T.B., Zimmermann, P.H., Spruijt, B.M., 2004. Working for food under conditions of varying motivation in broilers. Anim. Behav. 68, 105-113.

Bruce, E.H., Prescott, N.B., Wathes, C.M., 2003. Preferred food rewards for laying hens in behavioural experiments. Br. Poult. Sci. 44, 345-349.

Chance, P., 1999. Learning and Behavior. Brooks/Cole Publishing Company, USA, 505 pp.

Collier, G.H., Johnson, D.F., CyBulski, K.A., McHale, C.A., 1990. Activity patterns in rats (Rattus norvegicus) as a function of the cost of access to four resources. J. Comp. Psychol. 104, 53-65.

Cooper, J.J., Appleby, M.C., 1996. Demand for nest boxes in laying hens. Behav. Proc. 36, 171-182.

Cooper, J.J., 2004. Consumer demand under commercial husbandry conditions: practical advice on measuring behavioural priorities in captive animals. Anim. Welf. 13, S47-S56.

Cooper, J.J., Mason, G.J., 2000. Increasing cost of access to resources cause re-scheduling of behaviour in American mink (Mustela vison): implications for the assessment of behavioural priorities. Appl. Anim. Behav. Sci. 66, 135-151.

Cooper, J.J., Mason, G.J., 2001. The use of operant technology to measure behavioral priorities in captive animals. Behav. Res. Meth. Instrum. Comput. 33, 427-434.

Dawkins, M.S., 1983. Battery hens name their price: consumer demand theory and the measurement of ethological 'needs'. Anim. Behav. 31, 1195-1205.

Domjan, M., Burkhard, B., 1986. The Principles of Learning and Behaviour, second ed. Brooks/Cole Publishing Company, Monterey, CA.

Farstad, W., 1998. Reproduction in foxes: current research and future challenges. Anim. Reprod. Sci. 53, 35-42.

Fish, E.W., De Bold, J.F., Miczek, K.A., 2002. Aggressive behaviour as a reinforcer in mice: activation by allopregnanolone. Psychopharmacology 163, 459-466.

Foster, T.M., Blackman, K.A., Temple, W., 1997. Open versus closed economies: performance of domestic hens under fixed-ratio schedules. J. Exp. Anal. Behav. 67, 67-89.

Fox, M.W., 1971. Behaviour of wolves, dogs and related canids. Jonathan Cape Ltd., London.

Fox, M.W., 1975. Evolution of social behaviour in canids. In: Fox, M.W. (Ed.), The Wild Canids-Their Systematics, Behavioural Ecology and Evolution. Van Nostrand Reinhold Company.

Fraser, D., Matthews, L.R., 1997. Preference and motivation testing. In: Appleby, M.C., Hughes, B.O. (Eds.), Animal Welfare. CAB International, Wallingford, UK, pp. 159-173.

Hansen, C.P.B., Jeppesen, L.L., 2000. Effects of blocking farm mink's feed access with open water. Agric. Food Sci. Finl. 9, 157-163.

Hansen, S.W., Jensen, M.B., Pedersen, L.J., Munksgaard, L., Ladewig, J., Matthews, L., 2002. The type of operant response affects the slope of the demand curve for food in mink. Appl. Anim. Behav. Sci. 76, 327-338.

Harris, S., Smith, G.C., 1987. Demography of two urban fox (Vulpes vulpes) populations. J. Appl. Ecol. $24,75-86$.

Hodos, W., 1961. Progressive ratio as a measure of reward strength. Science 134, 943-944.

Holm, L., Jensen, M.B., Jeppesen, L.L., 2002. Calves' motivation for access to two different types of social contact measured by operant conditioning. Appl. Anim. Behav. Sci. 79, 175-194.

Hovland, A.L., Mason, G.J., Bøe, K.E., Korhonen, H.T., Bakken, M., 2005. Development of an operant apparatus for farmed foxes to measure motivation for access to social and environmental resources. In: Development and evaluation of an operant method to measure social motivation in farmed silver foxes (Vulpes vulpes), Dr. Scient. thesis 2005:14, Norwegian University of Life Sciences, ISBN 82-575-0656-7, ISSN 0802-3220.

Hurnik, J.F., Webster, A.B., Siegel, P.B., 1995. Dictionary of Farm Animal Behavior, second ed. Iowa State University Press, Ames, IA, USA, p. 116.

Hutson, G.D., van Mourik, S.C., 1981. Food preferences of sheep. Aust. J. Exp. Agric. Anim. Husb. 21, $575-582$.

Jensen, M.B., Munksgaard, L., Pedersen, L.J., Ladewig, J., Matthews, L., 2004a. Prior deprivation and reward duration affect the demand function for rest in dairy heifers. Appl. Anim. Behav. Sci. 88, 1-11.

Jensen, M.B., Pedersen, L.J., Ladewig, J., 2004b. The use of demand functions to assess behavioural priorities in farm animals. Anim. Welf. 13, S27-S32.

Katz, M.L., Rosen, H.S., 1998. Microeconomics, third ed. Irwin/McGraw-Hill. 
Kennedy, J.M., Baldwin, B.A., 1972. Taste preferences in pigs for nutritive and non-nutritive sweet solutions. Anim. Behav. 20, 706-718.

Kirkden, R.D., Edwards, J.S.S., Broom, D.M., 2003. A theoretical comparison of the consumer surplus and the elasticities of demand as measures of motivational strength. Anim. Behav. 65, 157-178.

Lea, S.E.G., 1978. The psychology and economics of demand. Psychol. Bull. 85, 441-466.

Littell, R.C., Milliken, G.A., Stroup, W.W., Russel, D., Wolfinger, R.D., 1996. SAS System for Mixed Models. SAS Institute Inc., Cary, NC, 633 pp.

Macdonald, D.W., 1979. Helpers in fox society. Nature 282, 69-71.

Mason, G., 1993. Age and context affect the stereotypies of caged mink. Behaviour 127, 191-229.

Mason, G.J., Cooper, J., Clarebrough, C., 2001. Frustrations of fur-farmed mink. Nature 410, 35-36.

Mason, G.J., McFarland, D., Garner, J., 1998. A demanding task: using economic techniques to assess animal priorities. Anim. Behav. 55, 1071-1075.

Matthews, L.R., Ladewig, J., 1987. Stimulus requirements of housed pigs assessed by behavioural demand functions. Appl. Anim. Behav. Sci. 17, 369.

Matthews, L.R., 1998. Using economic techniques to assess animal priorities: repays the investment. Anim. Behav. 55, 1076-1078.

Matthews, L.R., Ladewig, J., 1994. Environmental requirements of pigs measured by behavioural demand functions. Anim. Behav. 47, 713-719.

Narayana, N.S.S., Vani, B.P., 2000. Earnings and consumption by Indian rural laborers: analysis with an extended linear expenditure system. J. Pol. Mod. 22, 255-273.

Ng, Y.-K., 1990. The case for and difficulties in using 'demand areas' to measure changes in well-being. Behav. Brain Sci. 13, 30-31.

Osadchuk, L.V., 1999. A comparative study of sperm, sexual hormone concentrations and sexual activity in yearling and adult males of the silver fox. Anim. Sci. 68, 723-729.

Pedersen, L.J., Jensen, M.B., Hansen, S.W., Munksgaard, L., Ladewig, J., Matthews, L., 2002. Social isolation affects the motivation to work for food and straw in pigs as measured by operant conditioning techniques. Appl. Anim. Behav. Sci. 77, 295-309.

Pfaus, J.G., Kippin, T.E., Centeno, S., 2001. Conditioning and sexual behaviour: a review. Horm. Behav. 40, 291321.

Rachlin, H., Green, L., Kagel, J.H., Battalio, R.C., 1976. Economic demand theory and psychological studies of choice. Psychol. Learn. Motiv. 10, 129-154.

Raslear, T.G., Bauman, R.A., Hursh, S.R., Shurtleff, D., Simmons, L., 1988. Rapid demand curves for behavioral economics. Anim. Learn. Behav. 16, 330-339.

Sherwin, C.M., Nicol, C.J., 1995. Changes in meal patterning by mice measure the cost imposed by natural obstacles. Appl. Anim. Behav. Sci. 43, 291-300.

Sherwin, C.M., Nicol, C.J., 1996. Reorganization of behaviour in laboratory mice, Mus musculus, with varying cost of access to resources. Anim. Behav. 51, 1087-1093.

Trut, L.N., 1999. Early canid domestication: the farm-fox experiment. Am. Sci. 87, 160-169.

Varian, H.R., 1999. Intermediate Microeconomics: A Modern Approach. W.W. Norton \& Company, New York.

Von Schantz, T., 1981. Female cooperation, male competition, and dispersal in the red fox Vulpes vulpes. OIKOS 37, 63-68.

Warburton, H.J., 1999. Consumer Demand Theory and the Assessment of Animal Welfare. Ph.D. thesis, Department of Clinical Veterinary Science, University of Bristol.

Warburton, H.J., Mason, G., 2003. Is out of sight out of mind? The effects of resource cues on motivation in mink, Mustela vison. Anim. Behav. 65, 755-762.

Warburton, H.J., Nicol, C.J., 1998. Position of operant costs affects visits to resources by laboratory mice. Mus musculus. Anim. Behav. 55, 1325-1333.

White, P.C.L., Harris, S., 1994. Encounters between red foxes (Vulpes vulpes)—implications for territory maintenance, social cohesion and dispersal. J. Anim. Ecol. 63, 315-327.

Willford, J.A., Segar, T.M., Hansen-Trench, L.S., Barron, S., 1999. The effects of neonatal cocaine exposure on a play-rewarded spatial discrimination task in juvenile rats. Pharmacol. Biochem. Behav. 62, 137-143.

Zimmermann, P.H., Koene, P., van Hooff, J.A.R.A.M., 2000. The vocal expression of feeding motivation and frustration in the domestic laying hen, Gallus gallus domesticus. Appl. Anim. Behav. Sci. 69, 265-273. 